Original Article

\title{
DEVELOPMENT AND VALIDATION STABILITY INDICATING HPTLC METHOD FOR DETERMINATION OF VILDAGLIPTIN AND METFORMIN HYDROCHLORIDE IN THE PHARMACEUTICAL DOSAGE FORMS
}

\author{
ATUL R. BENDALE, R. P. SINGH, G. VIDYASAGAR
}

${ }^{1,2}$ Dept. of Pharmaceutical Sciences, Suresh Gyan Vihar University, Jaipur, Rajasthan, ${ }^{3}$ Pharmacy Department, Kutch University, Bhuj, Gujarat

Email: atulbendale123@gmail.com

Received: 06 Jun 2017, Revised and Accepted: 28 Nov 2017

\begin{abstract}
Objective: A simple, precise, and accurate stability indicating high-performance thin layer chromatography method was developed and validated of vildagliptin (VIL) and metformin (MET) in pharmaceutical dosage forms.

Methods: In the present study, system suitability test, stress study, alkali hydrolysis, acid hydrolysis, neutral hydrolysis, oxidative stress degradation, dry heat degradation, wet heat degradation, photodegradation study has been used. In this method, optimization by changing various parameters, such as organic solvent and the composition of the mobile phase, acid or base modifier used in the mobile phase; by varying one parameter and keeping all other conditions constant. $10 \mu \mathrm{l}$ of the stock solution for MET ( $500 \mathrm{ng} / \mathrm{band}$ ) and $2 \mu \mathrm{l}$ of the stock solution for VIL (100 ng/band) were applied to TLC plates. The final solutions were applied on the HPTLC plates and these were developed as per the optimized densitometry conditions.
\end{abstract}

Results: From the spectra, it was observed that MET and VIL exhibited good absorbance at about $217 \mathrm{~nm}$. Both the drugs showed degradation with additional peaks at $\mathrm{R}_{f}$ values of 0.16 for MET and with $\mathrm{R}_{f}$ values 0.81 for VIL respectively. The method was validated for linearity, precision, accuracy, limit of detection, limit of quantification, ruggedness, specificity, and robustness. Good separation was achieved by using the mobile phase Hexane: Methanol: Acetonitrile: Glacial Acetic Acid (2:3.5:2.5:0.2 v/v/v/v) with retardation factor ( $\mathrm{R}_{\mathrm{f}}$ ) values of 0.22 \pm 0.01 for MET and 0.73 \pm 0.02 for VIL.

Conclusion: A validated HPTLC method was developed for the determination of metformin hydrochloride and vildagliptin. The method is simple, quick, and can be applied routinely for the analysis of these drugs from marketed dosage forms.

Keywords: Metformin hydrochloride, Vildagliptin, Method validation, HPTLC

(C) 2018 The Authors. Published by Innovare Academic Sciences Pvt Ltd. This is an open access article under the CC BY license (http://creativecommons.org/licenses/by/4.0/] DOI: http://dx.doi.org/10.22159/ijap.2018v10i1.20555

\section{INTRODUCTION}

Metformin (MET) is known for its anti-diabetic properties, which is chemically, 1,1-dimethyl biguanide hydrochloride [1]. The important properties include; high efficacy, safety profile, beneficial cardiovascular and metabolic effects and therapeutic benefit in association with other antidiabetic drugs. Therefore metformin is included in first-line therapy to treat patients with type II diabetes mellitus [2]. In the present study, complimentary actions have drawn in focus to the usage of metal ong with a newer class of antidiabetic drugs, VIL the dipeptidyl peptidase (DPP)-4 inhibitors [1]. The literature survey reveals that several analytical methods are reported for quantitative estimation of metformin alone in body fluids and in pharmaceutical formulations. Those methods include spectrophotometry, electrochemical methods, HPLC, liquid chromatography-electrospray ionization tandem mass spectrometry and electrophoresis [3]. Reverse phase high performance liquid chromatographic method (RP-HPLC) for simultaneous estimation of metformin is also reported [4]. Studies have shown that age, gender, and body mass index (BMI) have no clinically relevant effects on the pharmacokinetics or pharmacodynamics of vildagliptin $[5,6]$ till time there is no noted HPTLC method for the estimation for vildagliptin and metformin hydrochloride combination in the pharmaceutical dosage forms. A synchronized improvement in $\beta$-cell function was also observed in subjects who had higher baseline HbA1C levels showed a greater response to metformin and vildagliptin treated patients [7, 8]. The present study was aimed to develop and validation stability indicating HPTLC method for determination of vildagliptin and metformin hydrochloride in the pharmaceutical dosage forms.

\section{MATERIALS AND METHODS}

Pure vildagliptin and metformin hydrochloride were procured from Matrix Pharma, Nashik, India as a gift sample. Acetonitrile, methanol, and water were all of HPLC grade procured from Merck Ltd., Mumbai, India. Potassium dihydrogen phosphate, hydrochloric acid, sodium hydroxide, anhydrous sodium acetate, glacial acetic acid, orthophosphoric acid were purchased from Priya scientifics, Vapi, India, were of analytical reagent grade.

\section{Preparation of solutions}

Stock standard solution VIL and MET was prepared by dissolving 7.5 mg VIL and 300 MET in methanol in a $50 \mathrm{ml}$ volumetric flask. Working standard solution of VIL and MET was prepared at a concentration of $15 \mathrm{ng} \mu \mathrm{l}-1$ and $600 \mathrm{ng} \mu \mathrm{l}-1$ respectively, by diluting the stock standard solution in methanol. The stock solution was stored at $2-8^{\circ} \mathrm{C}$ protected from light.

\section{Instrumentation}

The samples were spotted in the form of bands $6 \mathrm{~mm}$ width with a Camag 100 microlitre sample syringe (Hamilton, Bonaduz, Switzerland) on silica gel precoated aluminum plate 60 F254, $[(20 \times 10 \mathrm{~cm})$ with $250 \mu \mathrm{m}$ thickness; E. Merck, Darmstadt, Germany, supplied by Anchrom Technologists, Mumbai] using a Camag Linomat IV applicator (Switzerland). The plates were prewashed with methanol and activated at $110^{\circ} \mathrm{C}$ for $5 \mathrm{~min}$ prior to chromatography. A constant application rate of $0.1 \mu \mathrm{ls}-1$ was used and the space between two bands was $6 \mathrm{~mm}$. The slit dimension was kept at $5 \mathrm{~mm} \times 0.45 \mathrm{~mm}$ and the scanning speed was $10 \mathrm{~mm} \mathrm{~s}-1$. Linear ascending development was carried out in $20 \mathrm{~cm} \times 10 \mathrm{~cm}$ twin trough glass chamber (Camag, Muttenz, Switzerland) saturated with the mobile phase. The optimized chamber saturation time for mobile phase was $30 \mathrm{~min}$ at room temperature $\left(25 \pm 2{ }^{\circ} \mathrm{C}\right)$. The length of chromatogram run was 8 $\mathrm{cm}$. Densitometric scanning was performed using a Camag TLC scanner III in the reflectance-absorbance mode and operated by CATS software (V 3.15, Camag). The sources of radiation used were deuterium and tungsten lamp with a spectral range from 
190 to $800 \mathrm{~nm}$. Concentrations of the compound chromatographed were determined from the intensity of the diffused light. The evaluation was by peak areas with linear regression.

Selection of Analytical Wavelength A UV spectrum for the solution of VIL was recorded in a $10 \mathrm{~mm}$ cell over the range $200-400 \mathrm{~nm}$ using methanol in the reference cell. Isotretinoin showed maximum absorbance at $340 \mathrm{~nm}$ while MET was detected at $410 \mathrm{~nm}$.

\section{Optimization of mobile phase}

In an attempt to optimize the mobile phase, methanol-ethyl acetatetoluene-glacial acetic acid mixtures in different proportions were investigated. It was also observed that chamber saturation time and solvent migration distance were crucial in the chromatographic separation process; the chamber saturation time of less than $30 \mathrm{~min}$ and solvent migration distances greater than $80 \mathrm{~mm}$ resulted in the diffusion of the analyte band. The mobile phases used are shown in table 1.

Table 1: Optimization of mobile phase

\begin{tabular}{|c|c|}
\hline Mobile phase composition with their proportion & Result \\
\hline methanol: toluene: ammonia (9: $1: 0.5, \mathrm{v} / \mathrm{v} / \mathrm{v})$ & Very High $\mathrm{R}_{\mathrm{f}}$ value is not considerable and peak shape is broad \\
\hline methanol: toluene: glacial acetic acid $(8: 2: 0.5, \mathrm{v} / \mathrm{v} / \mathrm{v})$ & Very High $\mathrm{R}_{\mathrm{f}}$ value is not considerable \\
\hline methanol: toluene: glacial acetic acid (5: $5: 0.5, \mathrm{v} / \mathrm{v} / \mathrm{v})$ & Very low $R_{f}$ values obtained that were not considerable and peak shape is not sharp \\
\hline hexane: methanol: acetonitrile: glacial acetic acid (2.5: 3.5:3: & $\mathrm{R}_{\mathrm{f}}$ values were considerable but VIL $\mathrm{R}_{\mathrm{f}}$ value is more than 0.8 \\
\hline $0.1, \mathrm{v} / \mathrm{v} / \mathrm{v})$ & Peak shape of MET, VIL is improved \\
\hline $\begin{array}{l}\text { hexane: methanol: acetonitrile: glacial acetic acid }(2: 3.5 \text { : } \\
2.5: 0.2 \mathrm{v} / \mathrm{v} / \mathrm{v} / \mathrm{v}) \text {. }\end{array}$ & $\begin{array}{l}\text { MET and VIL were well resolved with peak purity of MET- } 0.998 \text { and VIL- } 0.997 \text { with } \\
\text { a sharp peak of MET and VIL. }\end{array}$ \\
\hline
\end{tabular}

VIL: vildagliptin; MET: metformin; v/v: volume by volume

The ratio of glacial acetic acid in the mobile phase had an effect mainly on the shape of the VIL and MET. Good separation was achieved by using the mobile phase hexane: methanol: acetonitrile: glacial acetic acid (2:3.5:2.5:0.2 v/v/v/v) with retardation factor $\left(R_{f}\right)$ values of $0.22 \pm 0.01$ for MET and $0.73 \pm 0.02$ for VIL. The $\mathrm{R}_{\mathrm{f}}$ values of MET and VIL was confirmed separately by applying on the TLC plate same concentration and same densitometry condition shown in fig. 1. For a selection of analytical wavelength for quantification of drugs, the standard spots were applied on silica gel and were scanned between 200 $400 \mathrm{~nm}$ and spectra obtained. From the spectra, it was observed that MET and VIL exhibited good absorbance at about $217 \mathrm{~nm}$, which was selected as the analytical wavelength for further analysis.

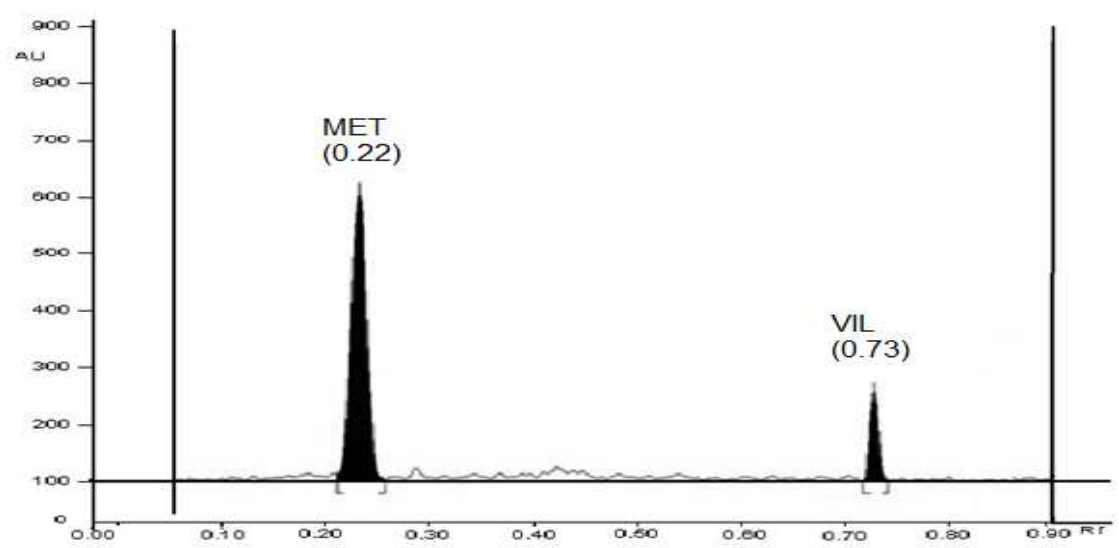

Fig. 1: Typical densitogram of metformin hydrochloride (MET $=0.22)$ and vildagliptin (VIL=0.73) standard in mixture solution

\section{RESULTS AND DISCUSSION}

The method was validated for linearity, precision, accuracy, limit of detection, limit of quantification, ruggedness. The International Conference on Harmonisation (ICH), US Food and Drug Administration (USFDA). US Pharmacopeia (USP) has published guidelines for method validation for analytical methods for pharmaceutical products. The most common validation parameters have been briefly described [9-15].

\section{System suitability}

The system suitability parameters like $R_{f}$ values, peak purity peak areas of VIL and MET were calculated.
System suitability tests were carried out on freshly prepared standard stock solutions of 200ng/band for MET and 50ng/ band for VIL and parameters obtained are summarized in table

\section{Stress study}

The stress studies were carried out under the conditions of hydrolysis, photolysis, oxidation and dry heat, as defined in the ICH guideline Q1A (R2).

These stock solutions of VIL and MET were used for forced degradation studies. The summary of stress study is shown in table 3 .

Table 2: System suitability test parameters

\begin{tabular}{lll}
\hline System suitability parameter & (MET) & (VIL) \\
\hline Peak Purity & 0.998 & 0.997 \\
$\mathrm{R}_{\mathrm{f}}$ value & $0.22 \pm 0.01$ & $0.73 \pm 0.02$ \\
Peak Area & $7082.74 \pm 36.63$ & $1673.3 \pm 9.53$ \\
\hline
\end{tabular}

VIL: vildagliptin; MET: metformin 
Table 3: Forced degradation studies data of vildagliptin and metformin hydrochloride by the developed HPTLC method

\begin{tabular}{|c|c|c|c|c|c|}
\hline \multirow[t]{2}{*}{ Stress condition } & \multirow[t]{2}{*}{ Time } & \multirow{2}{*}{$\begin{array}{c}\text { (MET) } \\
\text { \% assay }\end{array}$} & \multicolumn{3}{|c|}{ (VIL) } \\
\hline & & & \% degrade & \% assay & \% degrade \\
\hline Alkaline hydrolysis (1N NaOH) & $60 \mathrm{~min}$ & 82.80 & 17.20 & 90.85 & 9.15 \\
\hline Acidic hydrolysis $(1 \mathrm{~N} \mathrm{HCl})$ & $60 \mathrm{~min}$ & 93.43 & 6.57 & 93.52 & 6.48 \\
\hline Neutral hydrolysis(distill Water) & $120 \mathrm{~min}$ & 93.64 & 6.36 & 94.15 & 5.85 \\
\hline Oxidative degradation $\left(3 \% \mathrm{H}_{2} \mathrm{O}_{2}\right)$ & $240 \mathrm{~min}$ & 97.46 & 2.54 & 96.56 & 3.44 \\
\hline Dry heat $\left(80^{\circ} \mathrm{C}\right)$ & $240 \mathrm{~min}$ & 96.34 & 3.66 & 94.54 & 5.46 \\
\hline Wet heat (Boiling water bath) & $240 \mathrm{~min}$ & 98.53 & 1.47 & 97.52 & 2.48 \\
\hline Sun light & $72 \mathrm{hr}$ & 98.15 & 1.85 & 91.25 & 8.75 \\
\hline UV radiation $(254 \mathrm{~nm})$ & $240 \mathrm{~min}$ & 98.13 & 1.87 & 98.09 & 1.91 \\
\hline UV radiation $(365 \mathrm{~nm})$ & $240 \mathrm{~min}$ & 97.85 & 2.15 & 96.67 & 3.33 \\
\hline
\end{tabular}

VIL: vildagliptin; MET: metformin

The \% degradation was calculated by following formula:

$$
\% \text { Degradation }=\frac{\text { Initial area of untreated stock solution }- \text { Reduced area of treated stock solution }}{\text { Actual initial area of untreated stock solution }} \times 100
$$

\section{Alkali hydrolysis}

The base-treated stress degradation densitogram of VIL and MET in the mixture is as shown in fig. 2. Both the drugs showed degradation with additional peaks at $\mathrm{R} f$ values of 0.16 for MET and with $\mathrm{R} f$ values
0.81 for VIL respectively. MET was found to be $17.20 \%$ degraded in alkali medium while VIL was $9.15 \%$ degraded.

The peaks of the degradation products of both drugs were well resolved from the VIL and MET drug peaks [16-18].

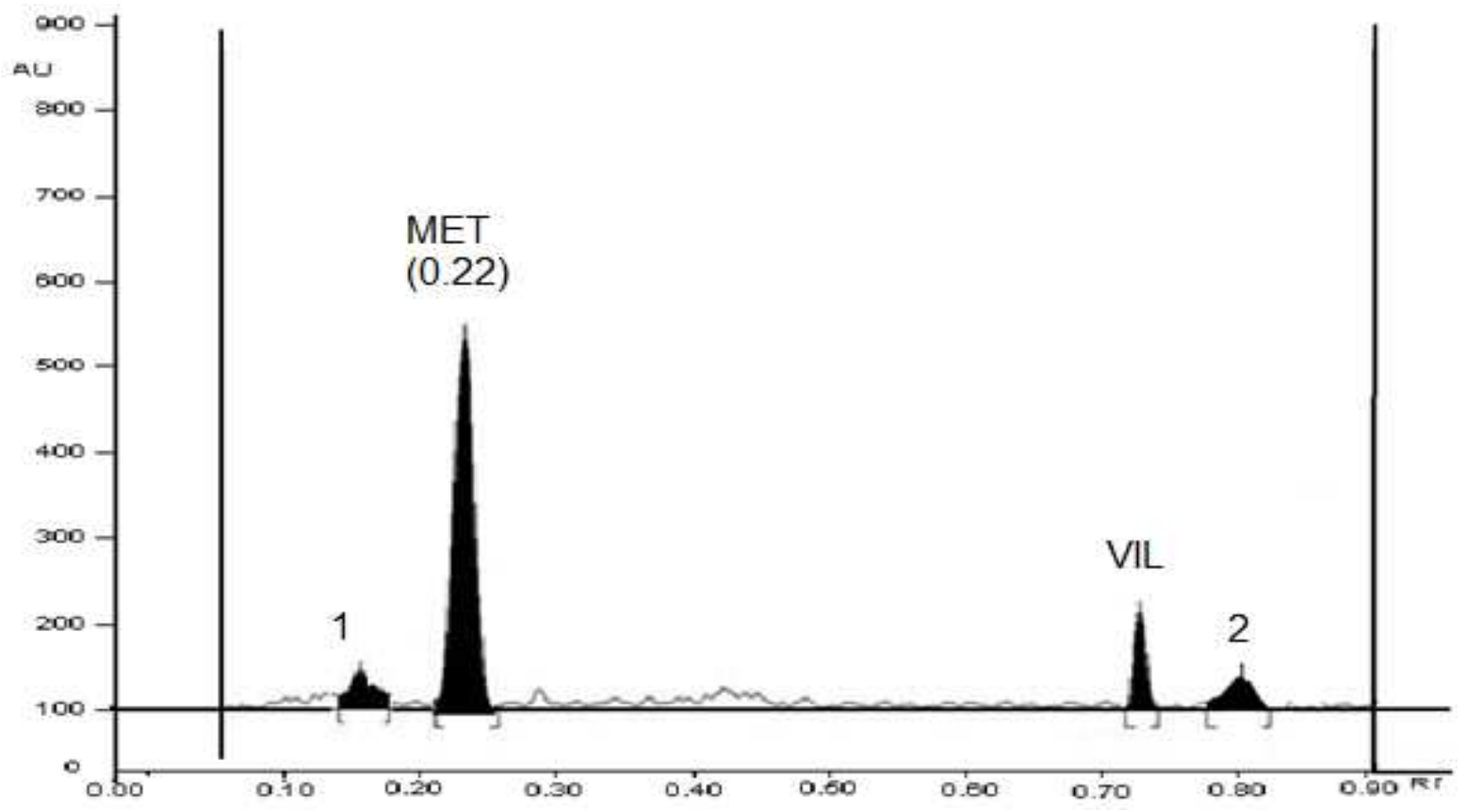

Fig. 2: Typical densitogram of vildagliptin and metformin hydrochloride and its degradation products in the alkali medium

\section{Acid hydrolysis}

The acid treated stress degradation densitogram of VIL and MET in the mixture is shown in fig. 3 and were found to undergo acid hydrolysis. Additional peaks at $\mathrm{R} f$ values of 0.16 respectively and 0.77 were observed for MET and VIL respectively. MET was found to be $6.57 \%$ degraded in acid medium whereas VIL was $6.48 \%$ degraded. The peaks of the degradation products of VIL and MET were well resolved from the VIL and MET drug peaks.

\section{Neutral hydrolysis}

Neutral hydrolysis study showed that VIL and MET were stable under neutral conditions. The neutral hydrolysis chromatograms of
MET and VIL were as shown in fig. 4. There was no additional peak observed.

\section{Oxidation-induced degradation study}

The oxidative stress degradation densitogram of MET and VIL in the mixture was as shown in fig. 5. The drugs were found to undergo slight oxidative degradation. Additional peaks at $\mathrm{R} f$ values of 0.16 and $0.75,0.77$ were observed for MET and VIL respectively. MET was found to be $2.54 \%$ degraded while VIL was $3.44 \%$ degraded under oxidative conditions.

The peaks of the degradation products of MET and VIL were well resolved from the MET and VIL peaks. 


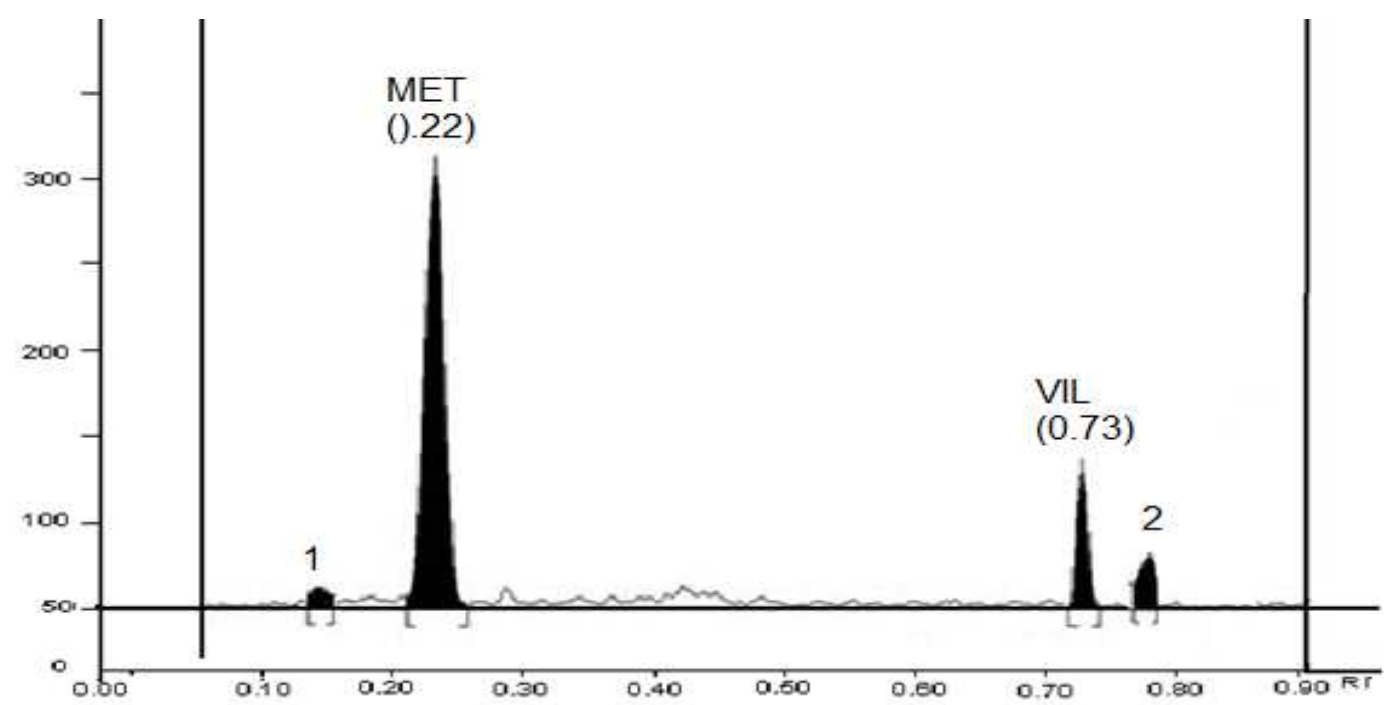

Fig. 3: Typical densitogram of vildagliptin and metformin hydrochloride and its degradation products in the acid medium

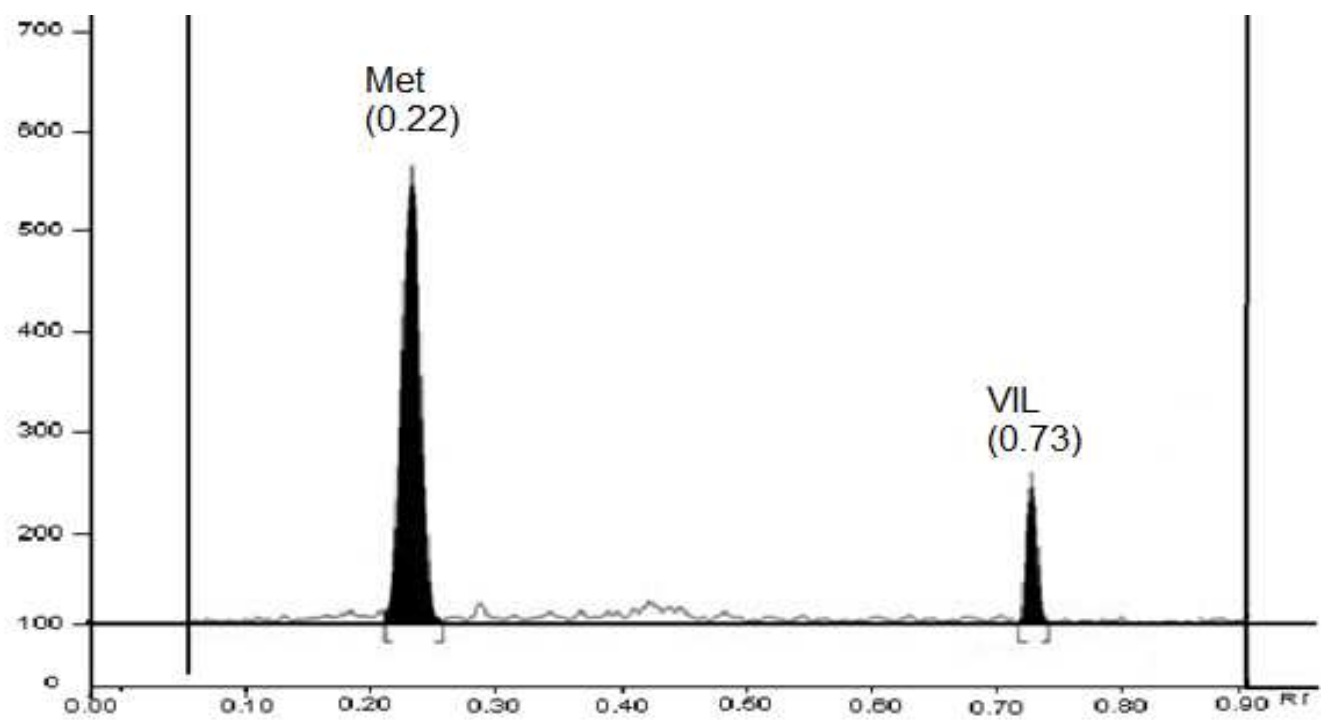

Fig. 4: Typical densitogram of vildagliptin and metformin hydrochloride and its degradation products in the neutral medium

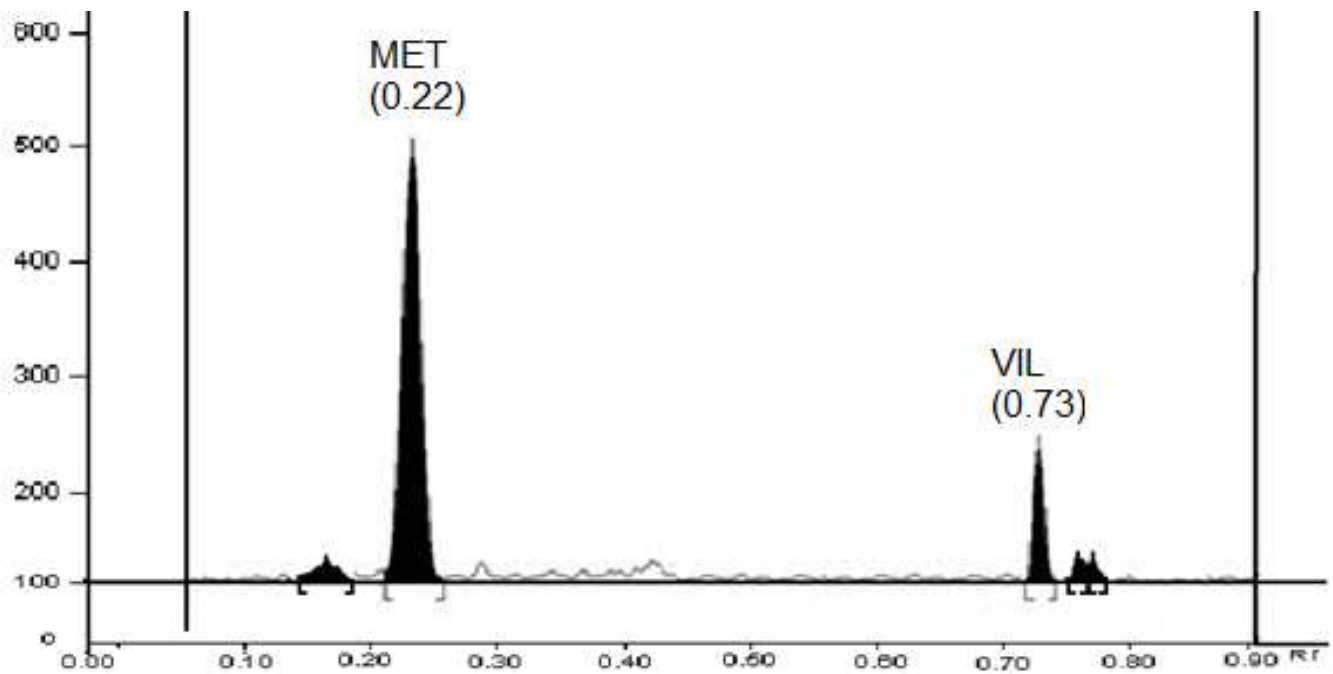

Fig. 5: Typical densitogram of vildagliptin and metformin hydrochloride and its degradation products in the oxidative medium 


\section{Thermal degradation (wet heat and dry heat) studies}

For dry heat degradation study solution of VIL and MET was stress at dry heated at $80{ }^{\circ} \mathrm{C}$ for $240 \mathrm{~min}$ in the oven. In the dry heat degradation study, it was found that MET and VIL were labile and additional peaks emerged at $\mathrm{R} f$ values of 0.32 and 0.83 for MET and VIL. MET was found to be $3.66 \%$ degraded and VIL was found to be $5.46 \%$ degraded. The peaks of the degradation products were well resolved from the drug peaks.

The wet heat stress degradation densitogram of MET and VIL in the mixture is shown in fig. 6 and it was found that MET and VIL were liable to wet heat degradation. Additional peaks at $\mathrm{R} f$ values of 0.32 (fig. 6) and 0.83 (fig. 6) for MET and VIL. MET was found to be $1.47 \%$ degraded whereas VIL was found to be $2.48 \%$ degraded. The peaks of the degradation products of MET and VIL were well resolved from the drug peaks.

\section{Photodegradation study}

Photodegradation of VIL and MET indicated they were quite stable in sunlight fig. 7. MET was found to be $1.85 \%$ degraded and VIL was found to be $8.75 \%$ degraded in direct sunlight stress condition.

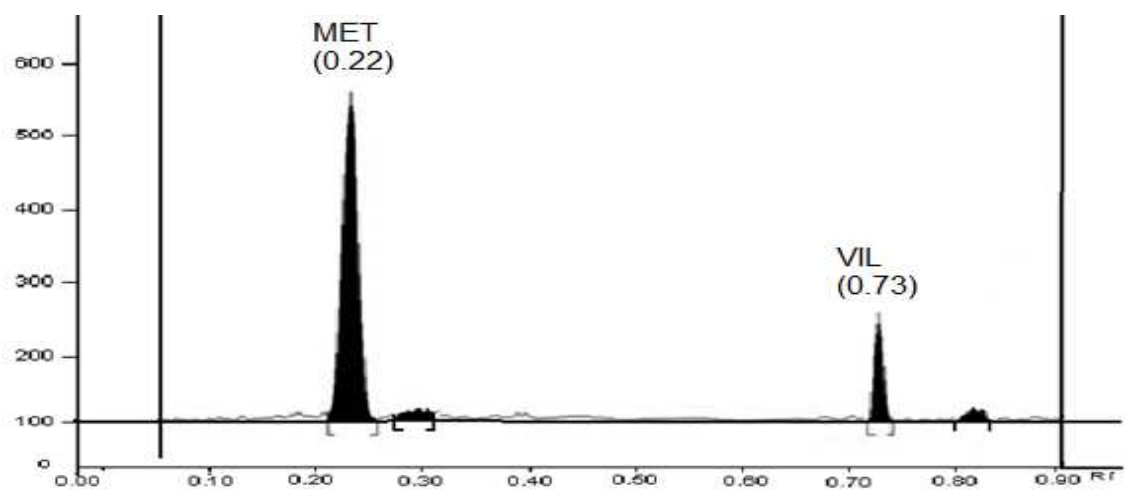

Fig. 6: Typical densitogram of vildagliptin and metformin hydrochloride and its degradation products after wet heat stress condition

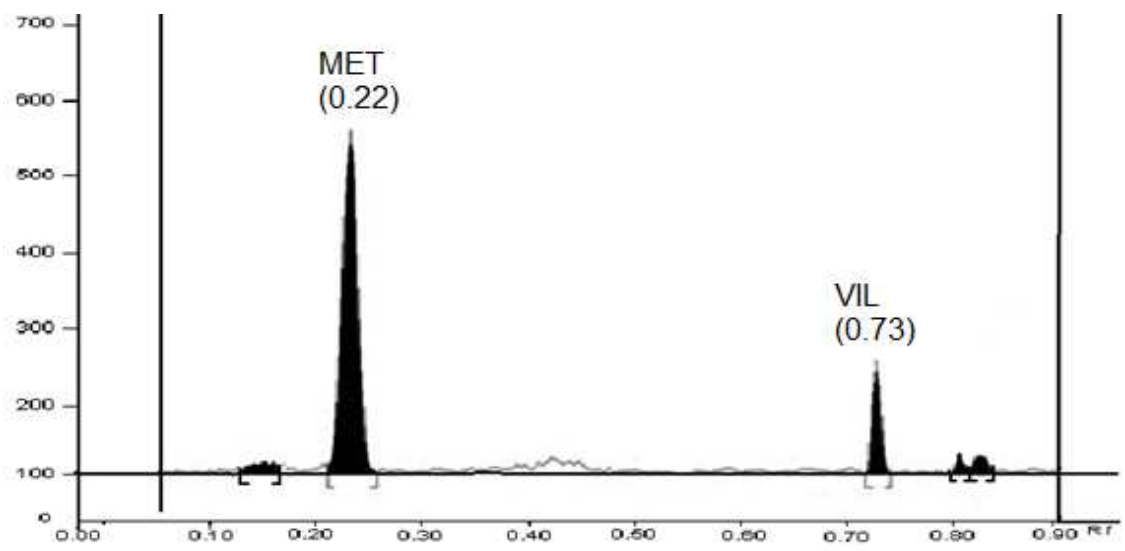

Fig. 7: Typical densitogram of vildagliptin and metformin hydrochloride and its degradation products after sunlight stress condition

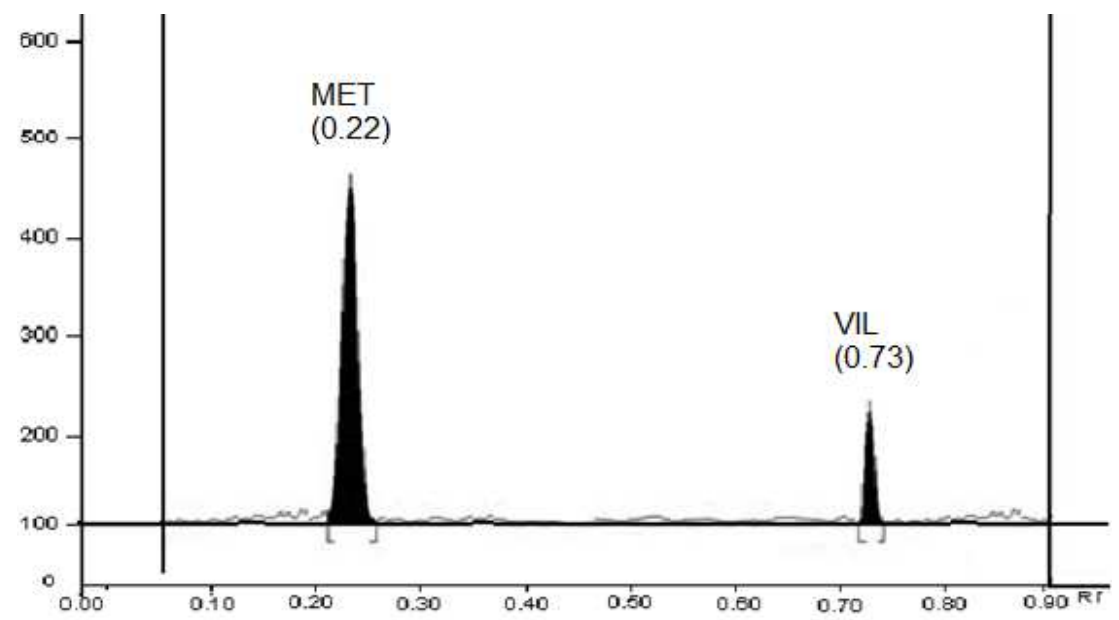

Fig. 8: Typical densitogram of vildagliptin and metformin hydrochloride and its degradation products after UV light (254 $\mathrm{nm}$ ) stress condition 
Furthermore, a stress degradation study in direct UV radiation was performed by exposing the solid drugs of MET and VIL and their mixture to UV radiation at 254 and $365 \mathrm{~nm}$. The UV light degradation (254 nm and $365 \mathrm{~nm}$ ) chromatograms of MET and VIL are shown in fig. 8. MET was found to be $1.87 \%$ degraded VIL was found to be $1.91 \%$ degraded in UV light $(254 \mathrm{~nm})$ stress conditions. MET was found to be $2.15 \%$ degraded VIL to be $3.33 \%$ degraded in UV light (365 nm) stress conditions. In photodegradation study and UV light degradation study of MET and VIL, no additional peak in
HPLC chromatograms was found only decrease in the peak areas of MET and VIL was observed.

Linearity and range (calibration curve for vildagliptin and metformin hydrochloride)

The calibration curves were obtained by plotting the peak area versus concentration over the range of 50-500 ng/band for MET and 10-150 $\mathrm{ng} / \mathrm{band}$ for VIL, respectively in mix standard. The calibration curve data of MET and VIL was shown in table 4 and table 5.

Table 4: Result of calibration curve for MET

\begin{tabular}{lll}
\hline Concentration (ng/band) & Peak area mean \pm SD & \% RSD \\
\hline 50 & $1786.24 \pm 64.74$ & 1.16 \\
100 & $3652.55 \pm 50.84$ & 0.82 \\
200 & $7082.62 \pm 74.24$ & 1.47 \\
300 & $10341.52 \pm 83.88$ & 1.23 \\
400 & $14542.28 \pm 96.69$ & 1.17 \\
500 & $17823.70 \pm 160.62$ & 1.55 \\
\hline
\end{tabular}

RSD: relative standard deviation; SD: standard deviation

Table 5: Result of calibration curve for VIL

\begin{tabular}{lll}
\hline Concentration (ng/band) & Peak area mean \pm SD & \% RSD \\
\hline 10 & $338.31 \pm 64.74$ & 1.61 \\
20 & $735.51 \pm 50.84$ & 1.23 \\
50 & $1678.26 \pm 74.24$ & 1.73 \\
100 & $3321.25 \pm 83.88$ & 1.31 \\
125 & $4355.81 \pm 96.69$ & 1.77 \\
150 & $5124.09 \pm 160.62$ & 1.85 \\
\hline
\end{tabular}

$\mathrm{a}=$ Average of three determinant $\backslash \mathrm{SD}=$ Standard deviation. \% RSD = Percentage relative

\section{Standard deviation}

The regression equation was found to be $\mathrm{y}=35.73 \mathrm{x}-27.35$ and correlation coefficient of 0.998 for MET. The regression equation was found to be $y=34.16 \mathrm{x}+1.352$ with a correlation coefficient of 0.999 for VIL. Each response was the average of three determinations. The statistical analysis data of calibration curve intercept, slope, and regression equation are shown in table 6.

Table 6: Statistical analysis data of calibration curve

\begin{tabular}{lll}
\hline Parameters & MET & VIL \\
\hline Linear range & $50-500 \mathrm{ng} / \mathrm{band}$ & $10-150 \mathrm{ng} / \mathrm{band}$ \\
Slope & 35.73 & 34.16 \\
Intercept & 27.35 & 1.35 \\
Regression coefficient ( ${ }^{2}$ ) & 0.998 & 0.999 \\
Standard deviation of slope & 0.179 & 0.826 \\
Standard deviation of intercept & 1.501 & 1.041 \\
LOD (ng/band) & 8.2 & 1.74 \\
LOQ (ng/band) & 27.06 & 5.74 \\
\hline
\end{tabular}

LOD = Limit of detection, LOQ = Limit of quantitation; VIL: vildagliptin; MET: metformin

\section{Precision}

The repeatability of developed method was determined by analyzing $200 \mathrm{ng} /$ band MET solution and $50 \mathrm{ng} /$ band VIL solution six times on the same day. The percentage RSD was found to be 1.5 for both the drugs. The results of the intermediate precision (Intraday precision and Interday precision) experiments are shown in table 7 for MET.

Table 7: Repeatability study

\begin{tabular}{|c|c|c|}
\hline Concentration & (MET) & (VIL) \\
\hline \multirow[t]{6}{*}{ Peak area } & 7302 & 1645 \\
\hline & 7323 & 1590 \\
\hline & 7094 & 1601 \\
\hline & 7188 & 1621 \\
\hline & 7134 & 1578 \\
\hline & 7356 & 1571 \\
\hline Mean & 7232.833 & 1601.000 \\
\hline SD & 108.754 & 27.878 \\
\hline$\%$ RSD & 1.5 & 1.7 \\
\hline
\end{tabular}

VIL: vildagliptin; MET: metformin; RSD: relative standard deviation; SD: standard deviation 
Replicate analyses of three different concentrations 50, 200 and 400 ng/band of MET solutions showed good reproducibility. The percentages RSD of intraday and interday studies were found to be $0.9-1.3 \%$ and $1.20-1.80 \%$ respectively for MET.

Replicate analyses of three different concentrations 10, 50 and 150 $\mathrm{ng} /$ band of VIL solution showed good reproducibility and the percentage RSD of intraday and interday studies were found to be $0.80-1.70 \%$ and $1.20-1.80 \%$ respectively for VIL.

Thus the developed method was found to be precise and repeatable on the basis of the mean $\mathrm{CV}$ values for the repeatability and intermediate precision studies which were $<2$ for VIL and MET respectively. The separations of the drug and various degradation products in a mixture of stressed samples were found to be similar when the analyses were performed with an LC system on different days.

Reproducibility of the developed method was determined by two different analysts under the same chromatographic condition and on same liquid chromatography instrument for the $200 \mathrm{ng} / \mathrm{band}$ for MET and $50 \mathrm{ng} /$ band for VIL concentration level respectively. The effect on the peak was evaluated by applying the F-test. There was no significant difference was found indicating that the developed method was reproducible. The reproducible results are shown in table 8 and 9 for MET and VIL respectively.

Table 8: Intraday and inter-day precision study for MET

\begin{tabular}{|c|c|c|}
\hline \multicolumn{3}{|l|}{ Intraday precision } \\
\hline Conc. (ng/band) & $($ Area $\pm S D)(n=3)$ & \%RSD \\
\hline 50 & $1794.67 \pm 25.01$ & 1.40 \\
\hline 200 & $7019.67 \pm 64.07$ & 0.90 \\
\hline 500 & $17815.33 \pm 303.27$ & 1.70 \\
\hline \multicolumn{3}{|l|}{ Interday precision } \\
\hline 50 & $1746.00 \pm 28.35$ & 1.60 \\
\hline 200 & $7059.33 \pm 86.82$ & 1.20 \\
\hline 500 & $17888.67 \pm 330.61$ & 1.80 \\
\hline
\end{tabular}

$\mathrm{n}=$ Three determination; RSD: relative standard deviation; SD: standard deviation

Table 9: Intraday and inter-day precision study for VIL

\begin{tabular}{lll}
\hline Intraday precision & & \\
\hline Conc. (ng/band) & (Area \pm SD) (n=3) & \%RSD \\
\hline 10 & $344.66 \pm 4.16$ & 1.20 \\
50 & $1590.00 \pm 27.07$ & 1.70 \\
150 & $5185.67 \pm 39.55$ & 0.80 \\
Interday precision & & 1.50 \\
10 & $360.34 \pm 5.51$ & 1.80 \\
50 & $1612.00 \pm 29.10$ & 1.20 \\
150 & $5219.67 \pm 61.45$ & \\
\hline
\end{tabular}

$\mathrm{n}=$ Three determination; RSD: relative standard deviation; SD: standard deviation

\section{Accuracy}

The recovery of the method was carried out by the standard addition to the pre-analysed test sample at three different concentration levels $80 \%, 100 \%$, and $120 \%$. Triplicate determinations were made at each concentration level. Known amounts of standards of MET $(0,160,200$ and $240 \mathrm{ng}$ per band) and VIL $(0,40,50$ and 60 ng per band) were spiked to a pre-quantified sample 200ng/band for MET and $50 \mathrm{ng} / \mathrm{band}$ for VIL and the mixtures were analyzed by proposed HPTLC method.

The percentage recovery of VIL and MET was determined by measuring the peak areas and fitting these values into the regression equation of the calibration plot. The recoveries were found to be 98.84-102.50 \% for MET and 99.08-103.60 \% for VIL, respectively. The values indicate that the method is accurate (table 10).

Table 10: Accuracy study

\begin{tabular}{|c|c|c|c|}
\hline Level & Drug added (ng/band) & Drug recovered (ng/band) $^{a}$ & $\%$ Drug recovered \pm SD \\
\hline \multicolumn{4}{|c|}{ Metformin hyrdochloride } \\
\hline 80 & 160 & 158.15 & $98.84 \pm 1.98$ \\
\hline 100 & 200 & 201.31 & $100.65 \pm 1.51$ \\
\hline 120 & 240 & 246.02 & $102.50 \pm 1.41$ \\
\hline \multicolumn{4}{|c|}{ Vildagliptin } \\
\hline 80 & 40 & 41.44 & $103.60 \pm 1.05$ \\
\hline 100 & 50 & 51.25 & $102.50 \pm 1.24$ \\
\hline 120 & 60 & 59.45 & $99.08 \pm 0.83$ \\
\hline
\end{tabular}

$\mathrm{a}=$ Average of three determination; SD: standard deviation

\section{Limit of detection and limit of quantitation}

The detection limits for MET and VIL were found to be 8.2 $\mathrm{ng} / \mathrm{band}$ and $1.74 \mathrm{ng} / \mathrm{band}$, respectively, while quantitation limits were found to be $27.06 \mathrm{ng} / \mathrm{band}$ and $5.74 \mathrm{ng} /$ band, respectively. This data indicates that a microgram quantity of both the drugs can be accurately and precisely determined. The values of LOD and LOQ of VIL and MET respectively indicate the sensitivity of the proposed method.

\section{Specificity and selectivity}

The peak purity index and HPTLC chromatogram showed peaks for both the drugs without any interfering peak and the estimation of both the drugs were found to be satisfactory. The test solution was prepared by mixing of VIL and MET with the tablet powder excipients. The peak purity of both drugs was assessed by comparing the respective spectra of standard drugs and samples at peak start, peak apex and peak end positions of the spot shown in fig. 9. 


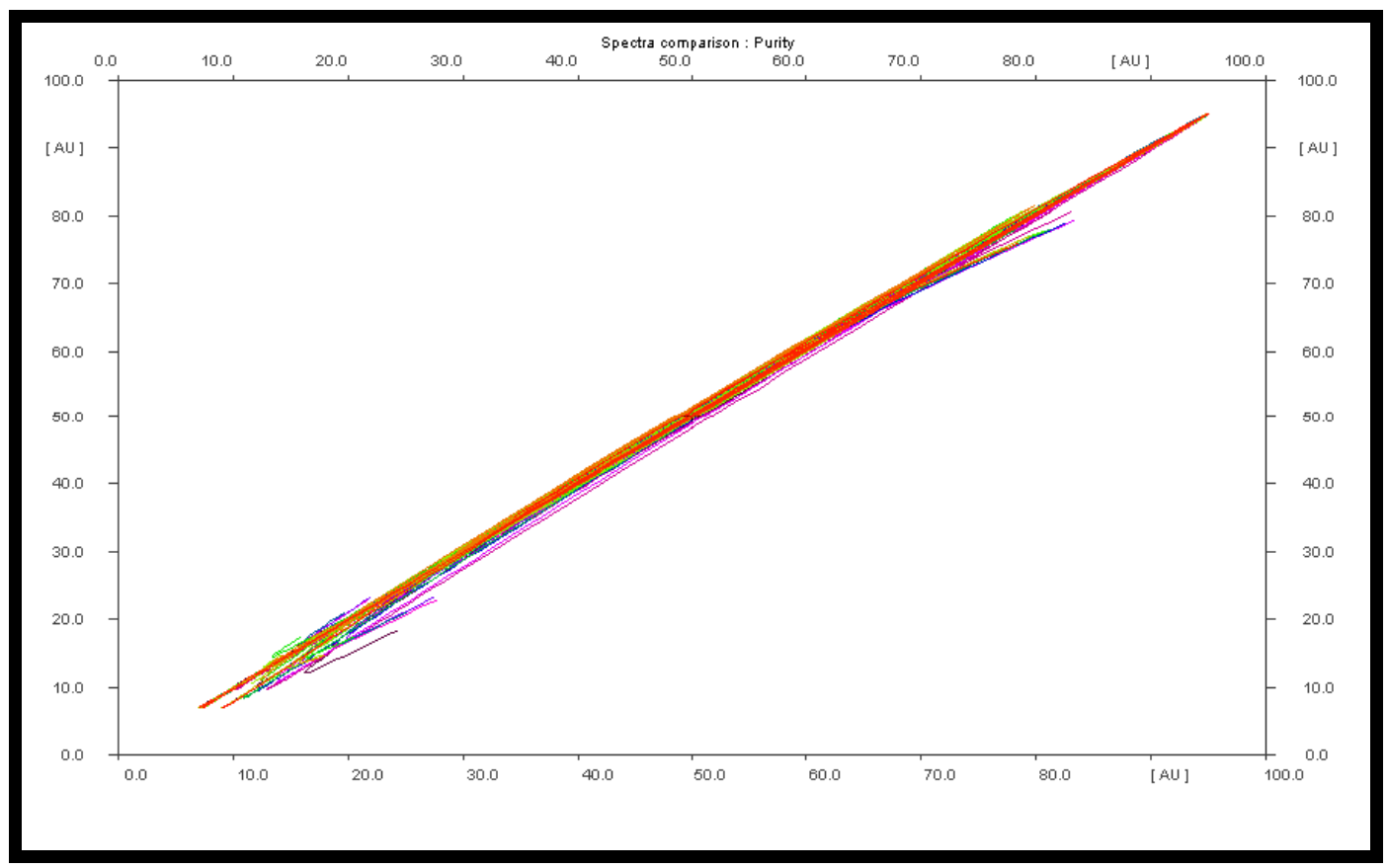

Fig. 9: Purity spectra of vildagliptin and metformin hydrochloride

Specificity is proven by comparing the chromatogram of diluent, standard solution, and test solution and by peak purity index to show that there was no any interference of excipients with the peak of VIL and MET (fig. 10).

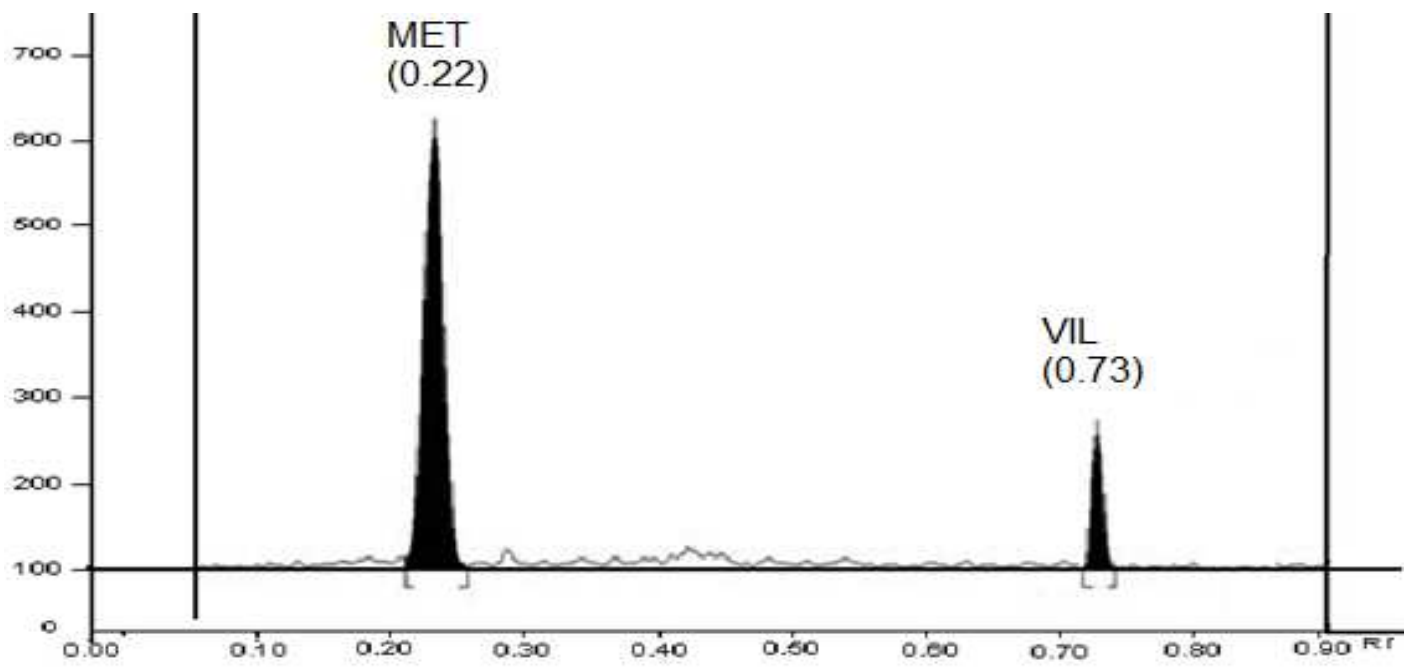

Fig. 10: Typical densitogram of vildagliptin and metformin hydrochloride in mix standard

The appearance of VIL and MET spots at specific Rf different from its degradation products indicated the specificity of the proposed method.

\section{Robustness}

The robustness of the method was evaluated by assessing the effect of variations in method parameters on peak areas of VIL and MET. The optimized densitometry conditions of mobile phase were hexane: methanol: acetonitrile: glacial acetic acid $(2: 3.5: 2.5: 0.2 \mathrm{v} / \mathrm{v} / \mathrm{v} / \mathrm{v})$, chamber saturation time is $30 \mathrm{~min}$, solvent migration distance is $80 \mathrm{~mm}$ and detection wavelength is $245 \mathrm{~nm}$. The small changes chamber saturation time is $25 \mathrm{~min}$ and $35 \mathrm{~min}$, and solvent migration distance is $70 \mathrm{~mm}$ and $90 \mathrm{~mm}$, and mobile phase composition was hexane: methanol: acetonitrile: glacial acetic acid (2.5:3.5:2:0.2 v/v/v/v and 2.5:3:2.5:0.2 v/v/v/v, 2:3:3:0.2 v/v/v/v) and the small changes in detection wavelength $240 \mathrm{~nm}$ and $250 \mathrm{~nm}$ were evaluated. After small changes in this parameter effect on the peak area of VIL and MET was determined. The low values of RSD indicated that the proposed method was robust, as small but deliberate changes in method parameters had no detrimental effect on the method performance as shown in table 11 . The low value of $\%$ RSD indicated that the method is robust.

\section{Solution stability}

The solution stability study revealed that VIL and MET solutions were stable for $48 \mathrm{~h}$ without detectable degradation. The percentage amount of both the drugs was found to be satisfactory (table 12). 
Table 11: Robustness study for MET and VIL

\begin{tabular}{|c|c|c|c|}
\hline \multirow[t]{2}{*}{ Parameters } & & MET (200ng/band) & \multirow{2}{*}{$\begin{array}{l}\text { VIL (50ng/band) } \\
\% \text { RSD }\end{array}$} \\
\hline & & \% RSD & \\
\hline \multirow[t]{3}{*}{ Changed proportion of mobile phase } & $2.5: 3.5: 2: 0.2$ & 1.39 & 2.19 \\
\hline & $2.5: 3: 2.5: 0.2$ & 1.48 & 1.23 \\
\hline & $2: 3: 3: 0.2$ & 1.05 & 1.71 \\
\hline Proportion of mobile phase used & $2: 3.5: 2.5: 0.2$ & 1.07 & 0.39 \\
\hline Changed & $70 \mathrm{~mm}$ & 1.25 & 1.88 \\
\hline migration distance & $90 \mathrm{~mm}$ & 1.40 & 1.60 \\
\hline Migration distance used & $80 \mathrm{~mm}$ & 0.70 & 0.89 \\
\hline Changed chamber & $25 \mathrm{~min}$ & 1.22 & 1.68 \\
\hline saturation time & $35 \mathrm{~min}$ & 1.49 & 1.56 \\
\hline Saturation time used & $30 \mathrm{~min}$ & 0.78 & 0.08 \\
\hline \multirow[t]{2}{*}{ Detection wavelength } & $240 \mathrm{~nm}$ & 1.28 & 1.31 \\
\hline & $250 \mathrm{~nm}$ & 1.05 & 1.41 \\
\hline Detection wavelength & $245 \mathrm{~nm}$ & 0.74 & 0.39 \\
\hline
\end{tabular}

VIL: vildagliptin; MET: metformin; RSD: relative standard deviation

Table 12: Solution stability study

\begin{tabular}{|c|c|c|c|c|}
\hline \multirow[t]{2}{*}{ Time } & \multirow[t]{2}{*}{ Area of METa } & \multirow[t]{2}{*}{ Area of GLI } & \multicolumn{2}{|c|}{$\%$ amount drug found $(n=3)$} \\
\hline & & & Area of MET & Area of GLI \\
\hline $0 \mathrm{~h}$. & 7382 & 1678 & 100.48 & 99.98 \\
\hline $4.0 \mathrm{~h}$. & 7123 & 1655 & 99.19 & 98.51 \\
\hline $8.0 \mathrm{~h}$. & 6854 & 1650 & 99.16 & 98.21 \\
\hline $24.0 \mathrm{~h}$. & 6988 & 1644 & 98.00 & 97.85 \\
\hline $48.0 \mathrm{~h}$. & 7034 & 1642 & 97.78 & 97.73 \\
\hline
\end{tabular}

a200ng/band for MET, b50ng/band for GLI

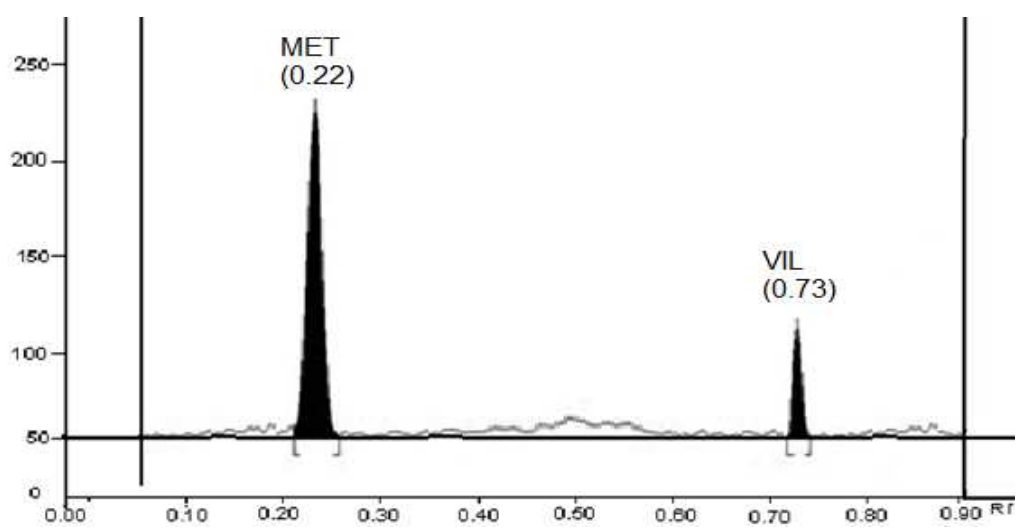

Fig. 11: Typical densitogram of MET and VIL in marketed formulation

The summary of method validation parameter and their result are shown in table 13 indicates that the developed method is validated as per ICH guidelines and result are within the ICH guidelines values.

Table 13: Summary of validation parameters

\begin{tabular}{lll}
\hline Parameters & MET & VIL \\
\hline Linear range & $50-500 \mathrm{ng} / \mathrm{band}$ & $10-150 \mathrm{ng} / \mathrm{band}$ \\
Regression coefficient & 0.998 & 0.999 \\
Regression equation & $\mathrm{y}=35.73 \mathrm{x}-27.35$ & $\mathrm{y}=34.16 \mathrm{x}+1.352$ \\
Recovery \% & $98.84-102.50 \%$ & $99.08-103.60 \%$ \\
Repeatability & 1.5 & 1.7 \\
(\%RSD, n=6) & & \\
Precision (RSD) & & $0.80-1.70 \%$ \\
Intra-day (n=3) & $0.9-1.3 \%$ & $1.20-1.80 \%$ \\
Inter-day (n=3) & $1.20-1.80 \%$ & 1.74 \\
Limit of Detection(ng/spot) & 8.2 & 5.74 \\
Limit of quantitation (ng/spot) & 27.06 & Robust \\
Robustness & Robust & Stable for $48 \mathrm{~h}$ \\
Solvent stability & Stable for $48 \mathrm{~h}$ & Specific \\
Specificity & Specific & 0.998 \\
Peak purity & 0.998 & \\
\hline
\end{tabular}

VIL: vildagliptin; MET: metformin; RSD: relative standard deviation 


\section{Analysis of marketed formulations}

The developed HPTLC method was successfully applied for the estimation of VIL and MET in the marketed dosage form. The marketed formulation, JALRA M 50/500 Tab and GALVUS M 50/500 Tab were analyzed using the developed HPTLC method. The chromatogram of tablet sample showed that at $\mathrm{R}_{\mathrm{f}}$ values of 0.22 and
0.73 for MET and VIL respectively, indicating that there was no interference of the excipients present in the tablet formulation.

The content of VIL and MET was calculated by comparing peak areas of samples with that of the standard. The marketed formulation was analyzed using proposed method which gave percentage recovery of more than 97.0 for VIL and MET (table 14).

Table 14: Assay results of marketed formulation

\begin{tabular}{lllll}
\hline Formulation & Drug & Amount taken (mg) & Amount found $^{\text {(mg) }}$ & \% MET \pm SD \\
\hline JALRA M Tab & MET & 500 & 505.55 & $101.11 \pm 1.87$ \\
& VIL & 50 & 48.65 & $99.00 \pm 1.18$ \\
GALVUS M Tab & MET & 500 & 490.55 & $98.11 \pm 1.72$ \\
& VIL & 50 & 51.45 & $98.54 \pm 1.21$ \\
\hline
\end{tabular}

VIL: vildagliptin; MET: metformin; SD: standard deviation

\section{CONCLUSION}

A validated HPTLC method was developed for the determination of metformin hydrochloride and vildagliptin. The developed method is simple, quick, and can be applied routinely for the analysis of these drugs from marketed dosage forms. The proposed method was found to be simple, precise, accurate, rapid and specific for determination of vildagliptin and metformin from pure and its dosage forms. The mobile phase is simple to prepare and economical. The sample recoveries in the formulation were in good agreement with their respective label claims and they suggested non-interference of formulation excipients in the estimation. Hence, this method can be easily and conveniently adopted for routine analysis of vildagliptin and metformin in pure form and its dosage form.

\section{AUTHORS CONTRIBUTIONS}

All the authors have contributed equally.

\section{CONFLICTS OF INTERESTS}

Declare none

\section{REFERENCES}

1. Havele S, Dhaneshwar S. Development and validation of a HPLC method for the determination of metformin hydrochloride, gliclazide and piogliglitazone hydrochloride in multicomponent formulation. Webmed Central Pharm Sci 2010;1:WMC001078.

2. Gopal NM, Sridhar C. A validated stability indicating a ultraperformance liquid chromatographic method for simultaneous determination of metformin hydrochloride and empagliflozin in bulk drug and tablet dosage form. Int J Appl Pharm 2017;9:45-50.

3. Kumar P, Vasudevan R, Deecaraman. A validated RP-HPLC method for simultaneous estimation of metformin and saxagliptin in tablets. Rasayan J Chem 2012;5:137-41.

4. Jayaprakash R, Natesan SK. Stability indicating RP-HPLC method development and validation for the simultaneous determination of vildagliptin and metformin in pharmaceutical dosage form. Int J Pharm Pharm Sci 2017;9:150-7.

5. Barden AT, Salamon B, Schapoval EE, Steppe M. Stabilityindicating RP-LC method for the determination of vildagliptin and mass spectrometry detection for a main degradation product. J Chromatogr Sci 2012;50:426-32.

6. Shaw RJ, Lamia KA, Vasquez D. The kinase LKB1 mediates glucose homeostasis in liver and therapeutic effects of metformin. Science 2005;310:1642-6.
7. El-Mir MY, Nogueira V, Fontaine E. Dimethyl biguanide inhibits cell respiration via an indirect effect targeted on the respiratory chain complex I. J Biol Chem 2000;275:223-8.

8. Rojas LB, Gomes MB. Metformin: an old but still the best treatment for type 2 diabetes. Diabetol Metab Syndr 2013;5:6.

9. Alam I, Jat RK, Singh R, Srivastava V, Srivastva S. Development and validation of reverse phased phase HPLC method for estmation ondansetron hydrochloride in bulk drug. Int Res J Pharm 2012;3:111-3.

10. Albert R, Horwitz W. Validation of analytical procedure. Anal Chem 1997;69:789-90.

11. Amin N, Seth A. Development and validation of stability indicating assay method for LNC and tramadol in tab. Dosage form by RPHPLC, Pharma Science Monitor. Int J Pharm Sci 2012;3:11-29.

12. Woolf AD, Pfleger B. Burden of major musculoskeletal conditions, theme papers. Bull World Health Organization 2003;81:646-56.

13. Beckett A. In practical pharmaceutical chemistry. Part II. CBS Pubmethers and Distributors; 1997. p. 275-337.

14. Bhatt P. Development and validation of stability indicating RPHPLC method for LNC in bulk drug. Int J Res Pharm Biomed Sci 2013;4:959-66

15. Bhavsar S. Validated RP-HPLC method for simultaneous estimation of LNC and THC in solid dosage form. J Chem Pharm Res 2010;2:563-72.

16. Bhusari V. Development of validated stability-indicating HPLC assay method for DKP. Int J Pharm Pharm Sci 2012;4:321-6.

17. Chaudhari BG, Trivedi JB. Simultaneous spectrophotometric estimation of THC and DKP in pharmaceutical dosage form. Int J Biomed Adv Res 2012;3:179-83.

18. Chitlange S. Simultaneous estimation of THC and aceclofenac in pharmaceutical dosage form by spectrophotometric and LC method. Der Pharm Lett 2010;2:86-93.

19. Choudhari V, Kuchekar B. Simultaneous spectrophotometric estimation of LNC and THC in combined dosage form. Res J Pharm Tech 2013;3:807-11.

20. Damodiya V, Singh R, Jat RK, Chokshi R. Method development and validation of terbinafine $\mathrm{HCl}$ in cream by RP-HPLC. Inventi Impact: Pharm Anal Qual Assur 2012;307:12.

21. Dhaneshwar S. Validated HPTLC method for simultaneous estimation of THC and aceclofenac in bulk drug and formulation. Int J Pharm Bio Sci 2011;2:482-90.

22. Goyal N, Bhandari A, Jain S, Patel R. Method development and validation of etoricoxib and THC in combined pharmaceutical solid dosage form by RP-HPLC method. Int J Pharm Studies Res 2011;2:106-9. 